\title{
XLIV. Analysis of the Bonnington water, near Leith, Scotland
}

\section{Edward G. Schweitzer Esq.}

To cite this article: Edward G. Schweitzer Esq. (1845) XLIV. Analysis of the Bonnington water, near Leith, Scotland, Philosophical Magazine Series 3, 26:173, 297-314, DOI: 10.1080/14786444508645134

To link to this article: http://dx.doi.org/10.1080/14786444508645134

册 Published online: 30 Apr 2009.

Submit your article to this journal $\sqsubset \pi$

Q View related articles $\longleftarrow$ 


$$
\begin{aligned}
\mathrm{V}_{1}= & \mathrm{PQ} \frac{b}{2} \cos \{n t-k(p x+s z)-\theta-\downarrow\}, \\
\mathrm{V}^{\prime}= & \mathrm{K} b e^{-k \chi z}\{\cos \{n t-k(p x+\sigma z)+x\} \\
& +\mathrm{PQ} \cos \{n t-k(p x+\sigma z)+x-\theta-1\}\} .
\end{aligned}
$$

Thus we have proved the laws above-stated for vibrations parallel to the plane of incidence.

[To be continued.]

XLIV. Analysis of the Bonnington Water, near Leith, Scot-
land. By EDWand G. SchweITzER, Esq.* TTHE soil from which this mineral spring rises, according 1 to the kind information obtained through G. Haig, Esq. of Bonnington House, is, for 20 feet below the surface, a wet, slipping sand of a yellowish colour, which is succeeded, for 20 feet, by a black hard clay, and this is followed, by a hard sandstone rock of considerable thickness, limestone of different qualities, and two small seams of coal; these have been bored, with very little interruption, through the extent of 184 feet. The mineral water when taken from the spring is quite transparent, with an empyreumatic smell, which it likewise imparts to the palate; it has also the taste of alkaline chlorides and iron. When a bottle containing the water for examination was opened, no disengagement of carbonic acid gas was perceptible, and when poured into a glass vessel but few bubbles of gas appeared at the sides; when mixed, however, with an acid, a slight discharge of carbonic acid gas took place. When exposed to the atmospheric air it becomes turbid, and a brownish sediment is formed; a few dark brown flakes were also floating in it, which were separately examined. The natural temperature of this water is abont $44^{\circ}$ Fahr., its specific gravity at $60^{\circ} \mathrm{F}$. is $1 \cdot 002618$, and the quantity emitted from the spring amounts to about from 4 to 5 gallons per minute.

It indicated no action upon blue litmus paper; when boiled it became turbid, oxide of iron with some crganic matter precipitated, and a slight alkaline reaction upon reddened litmus paper was developed. The usual well-known application of tests for a qualitative analysis evidenced the presence of potassa, soda, lime, magnesia, oxide of iron, sulphuric acid, chlorine, and carbonic acid gas.

- Communicated by the Chemical Society; having been read November 18,1844 . 
A portion of the water was concentrated by evaporation and divided into two parts; one of which, on being treated with fresh starch-paste and nitric acid, gave indication of iodine; the other part, when freed from iodine by nitric acid and æther, was mixed with a solution of chlorine and æther, which proved the existence of bromine. Nitrate of silver added to the mineral water gave a precipitate of chloride of silver, which became gray and afterwards purple, indicating organic matter, which was obviously demonstrated by the residue, after evaporating some of the water to dryness, becoming charred during ignition. Acetate of lead gave a yellowishwhite precipitate, proving the absence of hydrosulphuric acid. Caustic soda disengaged ammonia in abundance, which was evinced even by carbonate of soda.

The ingredients, which are present in very small quantities, were determined during the quantitative analysis, where a large volume of the water is evaporated, and consequently their detection rendered more easy.

It may not be irrelevant to mention an excellent test for nitric acid, when accompanied either by iodine or bromine, or both, its value being enhanced by the following results made respecting its action. It is known that the presence of nitric acid is easily indicated, when, to the concentrated fluid to be examined, pure sulphuric acid is added, and to this mixture a concentrated solution of the proto-sulphate of iron. The smallest trace of nitric acid, even the $\frac{1}{4000}$ th or $\frac{1}{5000}$ th part, is evidenced by the appearance of a pink colour, more or less intense. A large amount of nitric acid is indicated by a black colour, a combination of the oxide of nitrogen with the protoxide of iron ; however, here we have only to consider minute proportions. The salts of iodine and bromine, when treated with the same test, tinge the fluid with their own peculiar colour, but a greater addition of the solution of the proto-sulphate of iron destroys the colouring, which is not the case with nitric acid. If the quantity of nitric acid be very small, and that of iodine predominates, it is necessary for comparison to make a standard fluid, from which not only the presence of nitric acid may be inferred with certainty, but even its approximate quantity. For that purpose I employ 50 grs. of distilled water in which half a grain of iodide of potassium is dissolved, to this I add gradually $50 \mathrm{grs}$. of sulphuric acid, and afterwards 50 grs. of a concentrated solution of proto-sulphate of iron. The sulphuric acid precipitates the iodine, which is redissolved by the addition of the iron solution-forming an iodide of iron-whereby the fluid assumes a yellowish tinge, resembling the colour of a solution of chromate of potassa; 
the smallest proportion of nitric acid, however, should it even amount to $\frac{1}{300 \overline{0}}$ th part, will in this diluted state be manifested by a brownish tinge, which becomes much darker in proportion as the quantity of nitric acid increases. If a bromide be present instead of an iodide, the nitric acid can be ascertained with equal facility, from its imparting a greenish tinge to the fluid. $50 \mathrm{grs}$. of distilled water containing half a grain of an alkaline bromide to which 50 grs. of sulphuric acid have been added, will indicate $\frac{1}{2} \frac{1}{0} 0$ th part of nitric acid, by developing a brownish tinge, whereas a similar mixture without the nitric acid will remain colourless. This is obvious, as in the first instance, by the addition of the sulphuric acid, hydrobromic acid is formed, which is colourless, but becomes again decomposed by the presence of free nitric acid, whereby the fluid contracts a brownish tinge. The presence of both bromides and iodides does not interfere with the delicacy of this test for nitric acid, the reaction is the same as if an iodide only were present. However sure and delicate this test is, the presence of organic matter makes it complicated, and where the organic matter cannot be perfectly separated, the presence of nitric acid is easily overlooked, which indeed happened in this analysis at the first examination. In such cases I find the test with indigo* preferable; yet, where the quantity of nitric acid is very small, it is best to submit the concentrated fluid to distillation with sulphuric acid, as mentioned hereafter in the quantitative analysis, by which process the nitric acid was estimated.

It is obvious that a mineral water, containing a great number of ingredients, has to undergo a series of processes for the purpose of ascertaining the individual quantity of each, by which elaborate proceedings small proportions of them might be lost. It is therefore of paramount necessity to have, not only at the commencement of the analysis, but also during its progress, a means of control, which will confirm the correctness of the results of the analysis, and it is chiefly with this view that $I$ have edited this paper.

Alkaline mineral waters which have no volatile ingredients, such as ammonia, are to be controlled, regarding the total amount of their ingredients, by merely evaporating the water and igniting the residue; but if the water contains chiefly chlorides, and particularly earthy chlorides and chloride of ammonium, the mere evaporation, at a temperature approaching the boiling-point, is sufficient to drive off hydrochloric acid, and even ammonia, and if the water contains organic matter the control becomes still more difficult. As the Bonnington water presents these difficulties, they shall be pointed ont du-

* Rose's Handbuch der Analytischen Chonie, Band i. p. 235. 
ring the progress of the examination. It is indeed, under all circumstances, a very safe and necessary proceeding, to ascertain the weight of all the solid ingredients, and also the weight of some of the electro-negative substances, such as sulphuric acid, chlorine, \&c. This will give a proper control for those results which are afterwards obtained from the evaporated water. For this purpose,

1. Four troy ounces $(=1920$ grs.) of the water were supersaturated with hydrochloric acid, and, when boiling*, precipitated by chloride of barium.

$a$. Experiment gave $3 \cdot 622$ grs. of sulphate of barytes.

b. $\quad \cdots \quad \ldots \quad 3.602$ grs.

The average $=3.612$ grs., making for 16 troy ozs. of water $14: 448$ grs.

2. Four troy ounces of the water acidulated by nitric acid gave a precipitate with nitrate of silver, weighing-

$$
\begin{aligned}
& \text { a. Experiment . . . . } 10.030 \text { grs. } \\
& \text { b. } \quad . . \quad \text {. . . . } 10.077 \text { grs. } \\
& \text { The average }=10.053 \text { grs. }
\end{aligned}
$$

This precipitate however had been influenced by the organic matter, but this will be noticed again hereafter.

3. To ascertain the total amount of the solid ingredients, $1000 \mathrm{grs}$. were evaporated in a platina crucible, the residue dried at various temperatures, and the weight taken, when no further diminution was perceptible. The heated crucible was cooled over sulphuric acid, and then quickly weighed; a proceeding followed throughout the course of the analysis. The resulis were as follows:-

a. Residuet dried at $212^{\circ}$ Fahr. gave 3.712 grs.

b. $\quad \cdots \quad$ dried at $300^{\circ}$ to $310^{\circ}$ Fahr. gave 3.311 grs.

c. $\quad$... heated over a spirit-lamp till the evaporation of the ammonia had ceased, and as long as the escape of hydrochloric acid was perceptible, gave 2.339 grs.; from the charring of the organic matter the mass appeared black.

$d$. Residue heated to incandescence until the organic matter had been burned away, leaving the residue almost white, gave $2 \cdot 123$ grs.

From the above statement it is obvious that a very exact result cannot be obtained regarding the amount of the solid ingredients. 'The earthy chlorides require for their existence

* It facilitates very much the separation and lixiviation of the sulphate of barytes, when it is precipitated from a boiling menstruum, and the particles are thereby prevented fiom penetrating the pores of the filter.

+ This residue when placed in a humid atmosphere attracted water and became haif-fluid. 
a small proportion of water. Experiment $a$ gives therefore a wrong result, as they still contain this water, but in depriving them of it at a higher temperature some hydrochloric acid would be set free; moreover, as the existence of ammonia has been proved, it is impossible to dry the residue without a small loss of chloride of ammonium, so that experiment $b$ must give a result too low. Yet the truth of the result must lie within the limits of the experiments $a$ and $b$. The last two experiments, $c$ and $d$, from the destruction of organic matter, and the evolution of ammonia and hydrochloric acid, can be no guide whatever. An excellent control, which I frequently apply in various analyses, is to change the chlorides, carbonates, \&c. into sulphates; the total amount of the latter must closely approach the amount of the various ingredients obtained by analysis when computed as sulphates. This is a very satisfactory proceeding, and must give a correct result if the water does not contain ammonia, oxide of iron or alumina; the ammonia, however, being dissipated by heat must be deducted from the total amount of ingredients obtained by analysis, and as the oxide of iron and alumina (both losing a large quantity of sulphuric acid during ignition) are generally present in very small quantities, they will still allow of the above proceedings; but should they amount to any considerable quantity, as in some chalybeate and aluminous waters, this mode of control is not applicable. The residue which was derived from experiment $3 d$, amounting to 2.123 grs., was heated in a platina crucible with a sufficient quantity of sulphuric acid and ignited at a red heat, until all the ingredients were changed into neutral sulphates; it yielded $2 \cdot 663$ grs.

After these preliminary examinations the quantitative analysis was perfomed.

76.800 grs. were evaporated in a porcelain basin * with a proportionate quantity of chemically pure carbonate of soda, sufficient to decompose the earthy chlorides and sulphates. The application of carbonate of soda, besides preventing the escape of hydrochloric acid, affords another advantage, namely, it counteracts the formation of sulphate of lime, which is a very troublesome ingredient, inasmuch as it adheres closely to the vessel, and small quantities are not easily visible in a white porcelain basin; moreover, it is not soluble in hydrochloric

* The dark brown flakes which were floating in the water were collected and analysed by themselves, with the rinsing obtained from the glass bottles by hydrochloric acid, any oxide of iron that might adhere to the sides of the bottles being thus dissolved. The water contained only a small proportion of iron in solution. 
acid, and requires $461 \frac{1}{2}$ parts of water to re-dissolve it, whereas by the addition of carbonate of soda, the earthy carbonates, hereby produced, do not present any difficulty. For the above quantity of water it was found requisite to add $201.123 \mathrm{grs}$. of anhydrous carbonate of soda*; the whole was evaporated in a water-bath until a few ounces of fluid remained. It was then placed upon a filter, and the earthy residue A lixiviated with boiling water till the filtered liquor gave no indication of sulphates and chlorides. The fluid obtained from the edulcoration of the earthy residue $\mathbf{A}$ was evaporated, when some earthy particles were again separated, which were collected upon a filter B. It is here to be noticed, that by this method it is impossible to separate, with any degree of accuracy, the earthy ingredients from the soluble ones, as, by edulcoration, a small proportion of the former will always be redissolved; and however often this process may be repeated, whereby the quantity of the re-dissolved earthy ingredients will certainly be diminished, still the last traces of them cannot be obtained; moreover, the repeated evaporation of the lixiviating fluid must carry with it the unavoidable chances of loss : I therefore ascertain these traces of earthy ingredients by themselves along with the soluble salts. A small portion of the earthy carbonates adhered to the sides of the evaporating vessel; these were removed by hydrochloric acid, and the acid solution $\mathrm{C}$, hereby obtained, was left with the other earthy ingredients, $\mathrm{A}$ and $\mathrm{B}$, for further examination.

\section{Quantitative Analysis of the Soluble Ingredients.}

The fluid containing the soluble salts, and the edulcorating fluids $\uparrow$ obtained from the earthy ingredients, were evaporated to the weight of 8100 grs.

1. Earthy ingredients.--One-tenth of the fluid ( 810 grs.) was evaporated to dryness and the residue submitted to various temperatures, when the following results were obtained:-

At $212^{\circ}$ Fahr. . . . . . . . . $31.352 \mathrm{grs}$.

At $260^{\circ}$ to $280^{\circ}$ Fahr. . . . . . . 31.051 grs.

Ignited and fused over a spirit-lamp till the

organic matter was destroyed . . . $30.580 \mathrm{grs}$.

* By adding the carbonate of soda in solution to the mineral water, it is requisite to ascertain very exactly its quantity in the anhydrous state; the best method $l$ found is to change the carbonate into a sulphate, and to ignite the latter in an atmosphere of carbonate of ammonia, so as to dis. charge any possible surplus of sulphuric acid. If the carbonate of soda be ascertained as a carbonate, it must always be fused and quickly weighed.

+ It is always advisable to evaporate first the edulcorating fluids, and when properly concentrated, to mix them with the fluid which chiefy con. tains the dissolved ingredients. 
This residue was dissolved in water and effervesced by the addition of hydrochloric acid; it was evaporated, the residue moistened with hydrochloric acid, and after a few hours again dissolved in water, when a scarcely visible sediment separated. The acid fluid was supersaturated with ammonia; oxalate of ammonia gave no indication of lime, but phosphate of ammonia gave a small precipitate of the ammonio-phosphate of magnesia; this was edulcorated upon a filter with dilute ammonia, which prevents the re-solution of this salt, dried and ignited it gave $0.0309 \mathrm{gr}$.* of phosphate of magnesia, equivalent to 0.011 magnesia. Another mode of Berzelius, which gives likewise very exact results, I will briefly notice. The concentrated solution of the alkaline chlorides is to be evaporated to dryness with oxide of mercury. The chloride of magnesium is changed into magnesia, and chloride of nercury is produced, which latter unites with the alkaline chlorides. 'The further process is obvioust.

2. Sulphuric acid.-One-twentieth part of the fluid containing the soluble ingredients was acidulated by hydrochloric acid, and when boiling precipitated by chloride of barium. The sulphate of barytes weighed $7.201 \mathrm{grs}$. , which amounts upon 16 ozs, troy to 14.403 grs., equivalent to 4.950 grs. of sulphuric acid. If we compare this result with the one obtained by the preliminary experiments at 1 , it will be seen that it closely agrees.

3. Nitric acid. $-810 \mathrm{grs}$. of the fluid containing the soluble ingredients were very carefully neutralized by dilute sulphuric acid and macerated with a due proportion of sulphate of silver, in order to change the chlorides, iodides and bromides into sulphates $\ddagger$. The fluid separated from the silver precipitate was made alkaline by a little carbonate of soda, concentrated in a water-bath to a few ounces, and mixed in a tubulated retort with an adequate quantity of chemically pure sulphuric acid (previously boiled), more than sufficient to convert all the ingredients into bisulphates. This mixture was heated in a sand-bath and the vapours conducted into a glass receiver containing a solution of hydrate of barytes, and the distillation interrupted as soon as fumes

* I have to notice that I used the French gramme for ascertaining the weight of the ingredients, which I applied with precision to the first decimal number of a millegranme.

$\uparrow$ See Berzelius's Jahresbericht. 21st Jahrgang, 2nd Theil.

* A fluid containing a large amount of chlorides would require a very considerable quantity of the solution of sulphate of silver, inasmuch as this salt requires a great deal of water for its solution. To avoid this it is only necessary to mix the diluted fluid with the sulphate of silver, which has been previously triturated in a mortar with water, and to leave it for some time in a temperature not exceeding $100^{\circ} \mathrm{F}$. 
of sulphuric acid appeared. The fluid thus obtained was evaporated in a water-bath nearly to dryness, and the residue left for twelve hours exposed to the atmospheric air, in order to change the excess of hydrate of barytes into a carbonate*. After the separation of the carbonate of barytes the fluid was mixed with sulphuric acid, when 2.416 grs. of sulphate of barytes were obtained, equivalent to $1.1220 \mathrm{gr}$. of nitric acid.

4. Chlorine.-One-twentieth part, equal to 405 grs. of the fluid containing the soluble ingredients, was evaporated, and the residue fused to destroy the organic matter, and again dissolved. The solution supersaturated with nitric acid was precipitated by nitrate of silver. The precipitate was carefully collected upon a filter and lixiviated, first with water slightly acidulated with nitric acid, and afterwards with pure water. The dried precipitate was heated nearly to the point of fusing in a well-covered porcelain crucible, when $19.388 \mathrm{grs}$. of chloride of silver were obtained, making for 16 ozs. troy of water 38.776 grs. ; but, as will be seen hereafter, $0.126 \mathrm{gr}$. of bromide of silver and $0.010 \mathrm{gr}$. of iodide of silver are to be deducted from the amount $(38 \cdot 776-0.136)$, leaving $38^{\circ} 640 \mathrm{grs}$. of chloride of silver, equivalent to $9.533 \mathrm{grs}$. chlorine. If we compare the amount of the silver precipitate with that obtained from the preliminary experiment 2, we find a slight difference; the latter giving from two experiments in 4 ounces 10.053 grs., whereas the former, calculated upon the same quantity of water, gives $9 \cdot 694 \mathrm{grs}$. 'This discrepancy is accounted for, from the organic matter in the original water being partly thrown down with the silver precipitate. It is therefore requisite to free the fluid from its organic matter before the amount of its chlorides can be ascertained. The interference of organic matter with correct results is evidenced by the following experiments :-

a. Four troy ounces of the fresh water gave with nitrate of silver 10.053 grs.

b. Four troy ounces of the water evaporated with carbonate of soda and freed from the earthy carbonatest, gave with nitrate of silver $9 \cdot 883 \mathrm{grs}$.

c. Four troy ounces of the water evaporated with carbonate of soda and freed from the earthy carbonates, the filtered liquid again evaporated, the residue fused and again dissolved, gave with nitrate of silver $9 \cdot 694 \mathrm{grs}$.

5. Iodine.-4860 grs. of the fluid containing the soluble in-

* It is advisable to evaporate the fluid twice neariy to dryness, and filter each time, and to use for lixiviation as little water as possible, so as to prevent the solution of the carbonate of barytes.

+ A portion of the organic niatter followed the earthy carbonates. 
gredients were evaporated to dryness and the residue boiled four times with an adequate proportion of alcohol. [The residue after extraction showed no trace of iodine or bromine.] The alcoholic fluid was evaporated in a retort till an ounce remained, which, with the addition of a few grains of carbonate of soda, was evaporated to dryness in a platina crucible, the residue gently heated to a low red heat for the purpose of destroying the organic matter, again dissolved in water and filtered. The alkaline fluid thus obtained was very carefully neutralized by dilute hydrochloric acid; it held now in solution the whole amount of iodine and bromine. In my account of the analysis of the sea-water in the British Channel*, I described my method for separating iodine from bromine and chlorine. This method, though accurate, is more tedious than the method of Lassaigne, which was published after I had written that analysis. Lassaigne recommends to precipitate the iodine by chloride of palladium, and of this excellent and approved test I availed myself. Protochloride of palladium was added to the above fluid, which became at first turbid, but after the lapse of ten hours transparent, and a black-brown precipitate of protoiodide of palladium was obtained, which, when collected upon a filter, lixiviated and dried at $212^{\circ} \mathbf{F}$., amounted to $0.046 \mathrm{gr}$., equivalent to $0.060 \mathrm{gr}$. of iodide of silver, making for 16 troy ozs. of water $0.010 \mathrm{gr}$. of iodide of silver, equivalent to $0.005 \mathrm{gr}$. of iodine.

6. Bromine.-The fluid obtained after the separation of the protoiodide of palladium was saturated with hydrosulphuric acid gas to remove the excess of the palladium salt. Having separated by filtration the sulphuret of palladium the fluid was evaporated, the residue dissolved, the fluid filtered and concentrated by evaporation; to this solution was added a few drops of an ammoniacal solution of chloride of silver prepared thus: one part of a saturated solution of chloride of silver in ammonia, mixed with one part of ammonia and one part of water. A few drops of this mixture produced no turbidity in a saturated solution of chloride of sodium, but would indicate a very minute quantity of bromine. I refer for the further proceeding to my analysis of the sea-water in the British Channel. By this process $0.759 \mathrm{gr}$. of bromide of silver were obtained, making for 16 ozs. troy $0.126 \mathrm{gr}$., equivalent to $0.053 \mathrm{gr}$. of bromine.

7. Potassa.-810 grs. of the fluid containing the soluble ingredients were neutralized by hydrochloric acid and the sulphuric acid precipitated by chloride of barium. After the separation of the sulphate of barytes, the fluid was mixed

* See the London and Edinburgh Philosophical Magazine, No. 93, July 1839.

Phil. Mag. S. 3. Vol.26. No. 173. April 1845. Y 
with carbonate of ammonia and evaporated nearly to dryness, to free it from the surplus of the barytes salt. Having separated the carbonate of barytes, the fluid thus obtained was evaporated, and the residue heated to fusion in a well-covered crucible. The alkaline chlorides were dissolved in water and mixed with a surplus quantity of perchloride of platinum, and evaporated in a temperature of $175^{\circ} \mathrm{F}$. nearly to dryness; the residue was macerated with spirits of wine (containing $60 \mathrm{per}$ cent. of alcohol) as long as anything dissolved, when potassio-chloride of platinum was left behind weighing $6.036 \mathrm{grs}$, equivalent to $1 \cdot 167 \mathrm{gr}$. potassa.

8. Soda. - The usual way of ascertaining the amount of soda is by an indirect method. This has no difficulties with alkaline mineral waters; the amount of soda is obtained when the whole amount of the ingredients found by analysis in the fluid containing the soluble salts is deducted from the whole weight of the alkaline salts obtained by evaporation; however, this method cannot be applied where mineral waters have no alkaline carbonates, and where carbonate of soda has been added to the water, which by the presence of earthy chlorides, \&c. has been rarely changed into chloride of sodium.

The following method I employed here for ascertaining the soda by calculation:-It is requisite to arrange the ingredients established by analysis into binary combinations. Potassa, as the strongest and only base* ascertained, is united to sulphuric acid, and the surplus of the latter with the other electro-negative ingredients must therefore hnve been in combination with soda. The nitric acid has existed as nitrate of soda; this acid, however, in conjunction with organic matter at the high temperature at which the soluble ingredients were fused, has become decomposed, forming with soda carbonate of soda, an assumption established by facts.

grs.

1. $1 \cdot 167$ potassa give

2. 4.950 sulphuric acid,

less 0.991 united with potassa,

leaves $\overline{3.959}$ sulphuric acid, give $7 \cdot 047$ sulphate of soda.

3. $1 \cdot 12 \%$ nitric acill give

$1 \times 7697$ nitrate of soda,

equivalent to 1.106 carbonate of soda.

4. $9 \cdot 533$ chlorine give

5. 0.005 iodine give

6. 0.059 bromine give

7.

$2 \cdot 158$ sulphate of potassa.

$15 \cdot 798$ chloride of sodium. 0.006 iodide of sodium.

0.069 bromide of sodium. 0.011 magnesia.

\section{Total $\overline{26 \cdot 195}$}

* With the exception of a small quantity of magnesia which was united to soda. 
It will be seen, however, that the total amount of all the ingredients in an anhydrous state obtained at 1 , by the analysis of the earthy bases existing in the soluble salts, amounted to $30.580 \mathrm{grs}$.; deducting the above amount, $26.195 \mathrm{grs}$, there remains 4.385 grs. carbonate of soda, which is left unchanged of that quantity of carbonate of soda which was originally added to the mineral water when evaporated. If the soda added to 16 troy ozs. of the water be now deducted from the whole amount of the soda obtained by calculation, the exact quantity of soda existing in the water will be then ascertained.

$$
\begin{aligned}
& 7.047 \text { grs. of sulphate of soda }=3.088 \text { soda. } \\
& 1.106 \quad \ldots \text { carbonate of soda }=0.648 \quad \ldots \\
& 15.798 \quad \ldots \quad \text { chloride of sodium }=8 \cdot 418 \ldots \\
& 0.006 \quad \ldots \text { iodide of sodium }=0.001 \quad \ldots \\
& 0.069 \quad \ldots \text { bromide of sodium }=0.021 \quad \ldots \\
& 4.385 \quad \ldots \quad \text { carbonate of soda }=2.569 \quad \ldots \\
& \text { Total . } \overline{14 \cdot 745} \text { grs. }
\end{aligned}
$$

Carbonate of soda added $20.11230 \mathrm{grs} .=\operatorname{soda} \quad 11 \cdot 782 \ldots$

Leaving for soda existing in 16 troy ounces of mineral water. . . . . . . . . $2.963 \quad \ldots$

According to the foregoing analysis, the following soluble ingredients are obtained in 16 ounces troy of the water:-

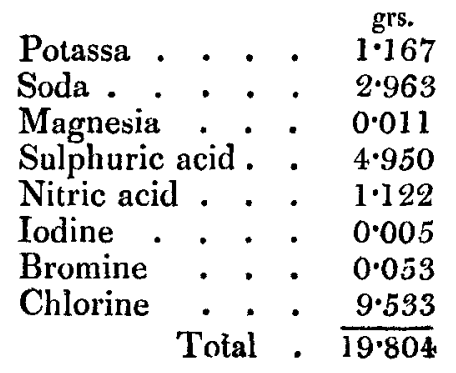

\section{Analysis of the Earthy Ingredients.}

By separating the soluble ingredients from the earthy carbonates, the precipitates $A$ and $B$ were obtained, and also an acid fluid $C$, which was boiled with an adequate quantity of carbonate of soda, the precipitate thrown down, well-lixiviated, placed in conjunction with $A$ and $B$ in a platina crucible*, and submitted to a temperature of $280^{\circ}$ to $300^{\circ} \mathrm{F}$. until

* Every filter was dried in a platina crucible at $212^{\circ} \mathrm{F}$., cooled over sulphuric acid, and its weight quickly taken in the same well-covered crucible. Where the nature of the precipitate or other circumstances did not admit of the combustion of the filter, I found it in most cases advantageous to remove the contents of the filter, still balf-moist, into a erucible, and to wash the last traces from the filter with a washing bottle. 
its weight did not alter; it gave $84 \cdot 301$ grs. The earthy carbonates were now dissolved very carefully in nitric acid, great care being taken that no loss was sustained during the effervescence, which is best obviated by covering the vessel with a convex glass, having in its centre a very small aperture for admitting the dilute acid to drop gradually into the vessel. The solution thus obtained was evaporated in a water-bath to dryness, (no action upon the glass that covered the platina vessel was perceptible, manifesting the absence of fluates, moistened with nitric acid, and left in that state for twelve hours, when it was re-dissolved. 'The substance which did not dissolve was lixiviated and boiled with hydrochloric acid, which left a perfectly white silica $(a)$, weighing 1.509 $\mathrm{gr}^{*}$. The acid fluid from $a$ was then carefully neutralized with ammonia, and, under the well-known precautions, precipitated by succinate of ammonia ; the precipitate was first lixiviated by very dilute ammonia, and afterwards with pure water, then carefully ignited with free exposure to the air, when $0 \cdot 105 \mathrm{gr}$. of oxide of iron $(b)$ was obtained. The fluid derived from $b$ was precipitated by hydrosulphate of ammonia; the precipitate, dissolved in hydrochloric acid and boiled with an adequate quantity of carbonate of soda, gave a precipitate, which, after lixiviation with boiling water and ignition, weighed $0.059 \mathrm{gr}$., and was red oxide of manganese $(c)$. The acid fluid obtained from $D$ was mixed in a closed vessel with ammonia, and after the precipitate had subsided, the supernatant fluid was quickly filtered, protected from the atmospheric air, and the precipitate $(\mathrm{E})$, lixiviated and ignited, weighed 11.819 grs. The menstruum from which this precipitate was obtained was only slightly acid, so that but a small amount of an ammonia-salt could be formed, and hence a larger amount of magnesia was precipitated, as will be hereafter seen. The precipitate (E) was dissolved in hydrochloric acid; it left $0.103 \mathrm{gr}$. silica $(d)$. The filtered fluid was mixed with bicarbonate of potassa, when a precipitate $(F)$ was formed. This precipitate was dissolved in hydrochloric acid, and the solution boiled with caustic soda; the precipitate $(\mathbf{G})$ thus formed, after lixiviation, was redissolved in hydrochloric acid and precipitated by ammonia, when $0.244 \mathrm{gr}$. oxide of iron $(e)$ was obtained, which dissolved in hydrochloric acid without residue and gave no indications of manganese. The menstruum from which this oxide of iron was precipitated gave with hydrosulphate of ammonia a few minute flakes of sulphuret of

* Very often the silica cannot be easily freed from traces of iron : in such cases it is requisite to fuse it with three or four times of its weight of carbonate of soda, and to dissolve it afterwards in hydrochloric acid. 
manganese, scarcely to be weighed. The caustic fluid* obtained from $\mathrm{G}$ was supersaturated by hydrochloric acid, when ammonia gave a precipitate $(f)$ of $0.134 \mathrm{gr}$. of alumina. The filtered fluid from the alumina was evaporated to dryness; the residue, after being heated till the ammoniacal salt was dissipated, left, when dissolved in water, a small trace $(g)$ of alumina, weighing $0.063 \mathrm{gr} . \dagger$ The fluid obtained from the precipitate (F) was neutralized by hydrochloric acid, and quickly evaporated with carbonate of potassa, and when nearly dry mixed with boiling water and filtered; the precipitate $(F)$ having been properly edulcorated with boiling water, weighed after ignition $10.857 \mathrm{grs}$, it was redissolved in hydrochloric acid and treated with hydrosulphate of ammonia; the precipitate hereby obtained was collected upon a filter, and gave after a similar treatment as $c, 0.043 \mathrm{gr}$. oxide of manganese $(h)$; deducting this amount from 10.857 , there remains 10.809 grs. of magnesia $(i)+$, equal to 22.372 grs. of carbonate of magnesia. The fluid obtained from the precipitate (F) still contained some traces of magnesia, it was therefore precipitated by anmonia and phosphate of ammonia, when the precipitate, after lixiviation with dilute ammonia and ignition, gave $1 \cdot 127$ gr. of phosphate of magnesia, equivalent to 0.413 magnesia $(k)$, equivalent to $0.854 \mathrm{gr}$. carbonate of magnesia. The ammoniacal fluid obtained from the precipitate (E) was next precipitated by oxalate of ammonia, and as soon as the precipitate had settled it was quickly filtered and lixiviated $\oint$. This precipitate (I) was ignited under the well-known pre-

* As caustic potassa or soda is seldom if ever quite free from traces of silica or alumina, $I$ ascertain, previous to the application of these tests, the quantity of the latter, for which a due deduction is made.

+ I have here to observe, that every ingredient obtrined was, after its weight had been ascertained, again examined for its purity. The alumina, as well as the oxide of iron, was examined before the blowpipe for phosphoric acid ; besides, these precipitates were dissolved in hydrochloric acid, precipitated by ammonia, and re-dissolved by a gentle heat in acetic acid, when after the lapse of one day no sediment had formed, evidencing the absence of phosphoric acid. The caustic fluid from which the last trace of alumina was separated was likewise tested for phosphoric acid, by adding to the fluid, neutralized by hydrochloric acid, chloride of calcium; but no trace of it was discernible.

$¥$ It is very difficult to separate the last traces of magnesia by carbonate of potassa; the fluid should be boiled quickly to dryness, and the residue lixiviated by boiling water. The fluid obtained from the residue shonld invariably be examined if it is free from magnesia. As in the above process the fluid containing the magnesia was not boiled to dryness, it accounts for the larger amount of magnesia obtained afterwards.

$\$$ When magnesia and lime are to be separated, both in considerable quantity, it is requisite to have the menstruum well-diluted, and to filter the oxalate of lime as soon as possible without interruption, so as to prevent the admixture of oxalate of magnesia. 
cautions for carbonate of lime, when it weighed 40.579 grs.; it was again dissolved in nitric acid, when $0.005 \mathrm{gr}$. silica $(l)$ was left. The solution of nitrate of lime gave no indications of manganese nor of strontia when the nitrate was changed into a chloride. [If earthy carbonates be dissolved in nitric acid, and tested for strontia by sulphate of lime, small quantities are not detected, but when the carbonates are changed into chlorides minute proportions are easily evidenced by that test.] Deducting 0.005 from 40.579, there remains 40.574 grs. of carbonate of lime $(m)$. The filtered fluid derived from (I) was now examined for magnesia. The simplest method would be to evaporate the fluid to dryness, and to ignite the residue until the ammoniacal salts are dissipated; however, this offers some difficulties, particularly as the mass on approaching the dry state rises and involves the probabilities of loss. It is therefore an advisable method to halve the fluid, and ascertain the quantity of magnesia in the one part by phosphate of ammonia, and in the other by evaporation, by which latter process also a few other ingredients, in very small quantity, which have hitherto escaped, may be found. One portion yielded, when precipitated by phosphate of ammonia, \&c., 10.34.4 grs. phosphate of magnesia, equivalent to 3.793 of magnesia. The other half was evaporated to dryness and the residue ignited, when it left $4 \cdot 186$ grs. of a perfectly white magnesia. This was boiled with water, which left after evaporation 0.370 gr. of carbonate of soda $(n)$, equivalent upon the whole mass to $0 \cdot 740 \mathrm{gr}$. When re-dissolved it acted strongly upon turmeric paper, effervesced with acids, and gave a very minute crystalline precipitate with perchloride of platinum, indicating that the soda contained a slight admixture of potassa. The soda was derived from a soda-carbonate of magnesia, which became decomposed by ignition, and from which boiling water extracted the soda*. The residue from which the carbonate of soda was separated was dissolved in hydrochloric acid, when again a small proportion of $0.010 \mathrm{gr}$. silica was left, making the whole silica $0.020(o)$. If the amount of silica $(0.010)$ and that of soda $(0.370)$ is deducted from $4 \cdot 186$, there remains $3.806 \mathrm{grs}$. of pure magnesia, which upon the whole gives magnesia 7.612 grs. $(p)$, equivalent to 15.759 carbonate of magnesia; this amount corresponds very closely with that obtained by the first experiment. The amount therefore of earthy ingredients obtained by analysis stands thus:-

* By performing the latter method of ascertaining magnesia, it is indispensably necessary to examine the oxalate of ammonia, which frequently yields after ignition traces of alkaline carbonates. 


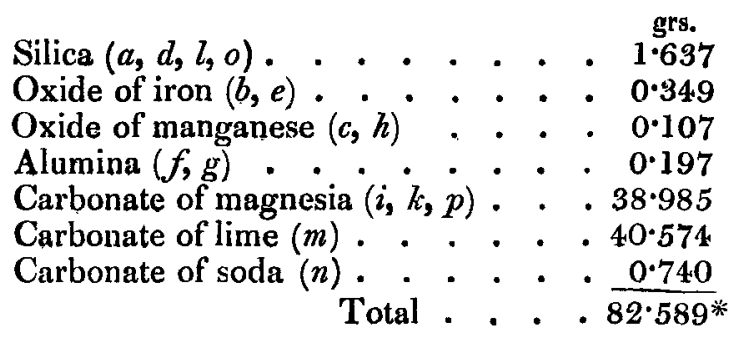

III. Analysis for the Carbonic Acid Gas and Ammonia.

1. Carbonic acid gas.-Before the above ingredients are computed to binary combinations, we have to ascertain the amount of carbonic acid gas and of ammonia. It is obvious that these two ingredients could not be ascertained from the evaporated water, and therefore new quantities of the mineral water had to be taken. For the analysis of the first 2880 grs. ( $=6$ ounces troy) of the water were precipitated by chloride of barium, and the precipitate collected upon a small filter ; this, while still wet and properly compressed, was introduced into a graduated tube over mercury with an adequate quantity of hydrochloric acid, previously saturated with carbonic acid gas. Having made a due reduction for the elasticity of the aqueous vapour, \&c.s $0.300 \mathrm{gr}$, were obtained, making for 16 ozs. $0.802 \mathrm{gr}$. of carbonic acid gas.

2. Ammonia. -3000 grs. of the mineral water were introduced into an appropriate tubulated glass retort, and mixed with half an ounce of caustic sodn. The vapours were, during distillation, conducted under dilute hydrochloric acid, and the operation finished, when only 2 ounces were left in the retort. The distilled fluid previously mixed with chloride of platinum was evaporated in a porcelain vessel. [I have to notice, that without this addition of the chloride of platinum no correct results can be obtained, even at a temperature below $212^{\circ} \mathrm{Fahr}$, inasmuch as the chloride of ammonium rises with the aqueous vapours. This is easily ascertained by covering the vessel during evaporation with filtering paper, which when lixiviated will clearly evidence the presence of chloride of ammonium, a circumstance which Berzelius has already noticed in his Manual of Chemistry, vol. x.] The dry residue was lixiviated by a mixture of 2 volumes of alcohol and 1 volume of ather, in which mixture the ammonio-chloride of platinum is perfectly insoluble. The edulcoration was carried on until all acid reaction upon litmus paper ceased, when the precipi-

* An amount which comes near to 84.301 grs., but of course free from organic matter, which the latter amount includes. 
tate was dried at $212^{\circ}$ Fahr, and weighed 15.406 grs. To control the correctness of the weight, the precipitate and filter were placed in a platina crucible, and ignited in the manner described by $\mathrm{H}$. Rose in his Analytical Manual, when 6.8138 grs. of platina were obtained, which corresponds with the amount of platina derived by calculation from 15.406 grs., viz. 6.814.2 grs. The amount of ammonia calculated from these data for 16 ounces is 3.033 grs.

If we now arrange the electro-negative and electro-positive ingredients, thus established, into binary combinations in the ratio of their mutual affinities, it will be found that there is a surplus of bases, one of which must obviously be united to the organic matter; and I am inclined to think that a combination of ammonia and organic matter has existed. I regret that the small quantity of water ( 12 wine bottles) obtained for analysis from Scotland did not permit me to study the nature of the organic matter, but there is no doubt that it belonged to the group of decaying substances. The few experiments $I$ was enabled to perform evidenced the absence of crenic and apocrenic acid, namely, when the water was evaporated to one-tenth of its volume, neutralized by acetic acid, and mixed with acetate of copper and heated, no indication of these acids was perceptible. Acetate of lead gave a precipitate; it did not however separate the organic matter entirely. That the source of ammonia stands in intimate connection with that of the organic matter admits scarcely of doubt, particularly since Mulder* and R. Herrman of Moscow have established that some of the class of humus acids contain ammonia. If mouldering wood, garden-earth, \&c. are extracted by alcohol and then with water, and the residue treated with alkalies, a humus acid is obtained, which, besides carbon and the elements of water, contains a certain proportion of ammonia in chemical combination. By the analysis of such an acid derived from the soil of a meadlow, the following results were obtained, expressed in this formula:-

$$
2 \mathrm{~N}_{2} \mathrm{H}_{6} \mathrm{OH}_{2}+\mathrm{C}_{40} \mathrm{H}_{28} \mathrm{O}_{14}
$$

Mulder's analyses prove also that in a fertile soil combinanations of ammonia with those acids exist, derived from the decay of vegetable matter; but these acids correspond with humus acid, inasmuch as they have the same number of equivalents of carbon (40), but vary in the proportion of oxygen and hydrogen. It is obvious from the foregoing results, that mineral waters containing alkalies, when they come in contact with strata interspersed with humus, must become partly im-

* See Berzelius's Jahresberichl, 21st Jahrgang, 3rd Heft. 
pregnated with ammonia and these organic acids, produced by the decay of vegetable matter.

The result of the analysis gives the following binary combinations in $16 \mathrm{oz}$. troy of the water:-

Anhydrous ingredients.

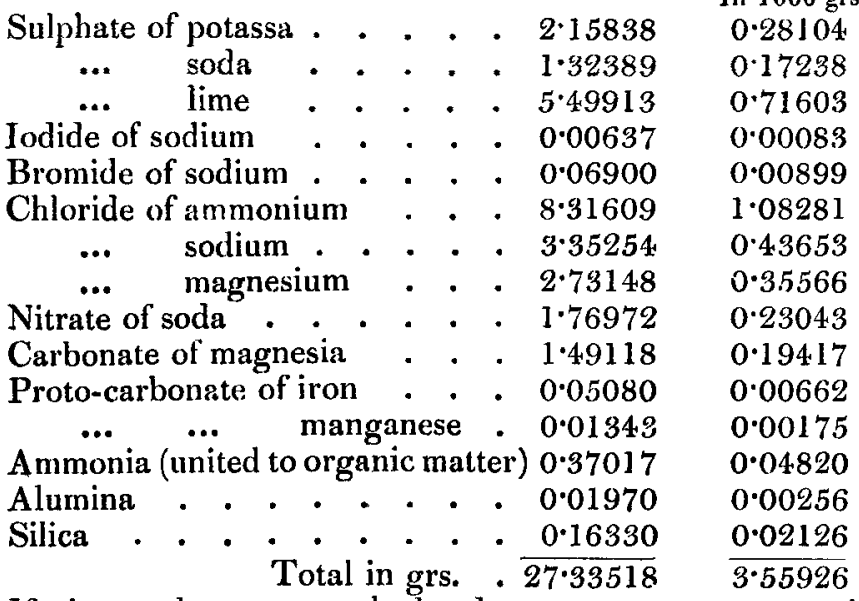

If the total amount calculated upon 1000 grs., namely, $3.559 \mathrm{grs}$. is compared with that obtained by the evaporation of 1000 grs. -3.712 grs. - we find a deficiency of $0.153 \mathrm{gr}$., which belongs to the organic matter; yet it is to be observed, that the amount 3.712 cannot be very exact, as during evaporation a small proportion of ammonia must have been dissipated. To prove if the results of the analysis of the fixed bases are correct, they were computed to sulphates and compared with the result obtained by evaporating 1000 grs. of the water, igniting the residue to a red heat, and mixing it with a due quantity of sulphuric acid, and again igniting it until the surplus of sulphuric acid was dissipated, when it yielded $2 \cdot 663$ grs.

Changing in this way the fixed ingredients into sulphates, by computation we have-

\begin{tabular}{|c|c|c|c|c|}
\hline \multicolumn{5}{|c|}{ Sulphate of potassa } \\
\hline & soda & $\bullet$ & - & 6.930 \\
\hline$\ldots$ & lime. & . & . & $5 \cdot 4.99$ \\
\hline$\ldots$ & magnesia & . & • & $5 \cdot 569$ \\
\hline$\ldots$ & alumina & • & $\bullet$ & 0.065 \\
\hline Proto-su & late of iro & & & 0.067 \\
\hline$\cdots$ & ... & & & I \\
\hline ica & - . & . . & - & $0 \cdot 163$ \\
\hline
\end{tabular}

This amount gives upon 1000 grs. $2 \cdot 665$, a result very close 


\section{Mr. Drach on Observation-Hours for Meteorologists.}

indeed to $2 \cdot 663$, as obtained by experiment, where the iron, manganese and alumina might have lost during ignition a small quantity of sulphuric acid.

A few small flakes, which were found floating in the water, and which were separated, remain finally to be noticed. These fiakes consisted chiefly of oxide of iron with a small proportion of organic matter. The oxide of iron upon 16 ozs. amounted to $0.384 \mathrm{gr}$., which had become separated (as I was assured) from the water in the bottles, and must have existed previously in the form of a proto-carbonate of iron, which would be equivalent to the amount of 0.56175 . On adding this to the iron found in solution, 16 troy oz. of the water would contain at its source $0.61255 \mathrm{gr}$. of proto-carbonate of iron, or in 1000 grs. $0.07975 \mathrm{gr}$.

For convenience sake the calculation upon the imperial pint is added.

In 1 pint $=34.659$ cubic inches (at $60^{\circ} \mathrm{F}$. spec. grav. $1 \cdot 002618)=8772 \cdot 907 \mathrm{grs}$.

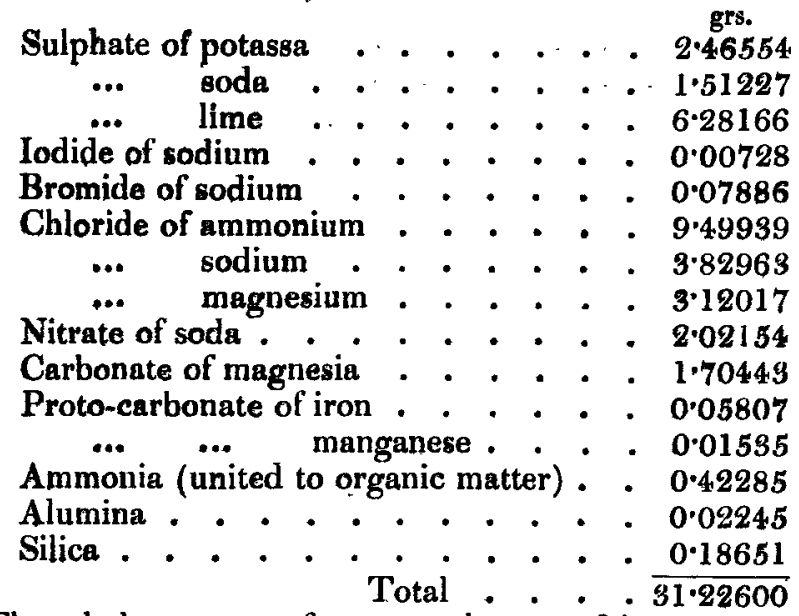

The whole amount of proto-carbonate of iron in 1 pint at the source $=0.69973 \mathrm{gr}$.

XLV. On Observation-Hours convenient to Amateur Meteorologists, and adequate for obtaining Mean Values. By S. M. Drach, Esq., F.R.A.S.*

7 THIS important selection for the furtherance of meteoro1 logy by those whose avocations do not permit of conti . nual attention to their instruments, having been expatiated

- Communicated by the Author. 